\title{
Sexual dysfunction in epilepsy patients attending a tertiary care hospital
}

\author{
Mahendra Javali ${ }^{1, *}$, Shripal Shah ${ }^{2}$, Shivaraj NS ${ }^{3}$, Srinivasa ${ }^{4}$, Purushottam Acharya ${ }^{5}$ \\ ${ }^{\mathbf{1}}$ Associate Professor, ${ }^{\mathbf{2}}$ Consultant, ${ }^{\mathbf{3}}$ Assistant Professor, ${ }^{\mathbf{4}}$ Professor, ${ }^{\mathbf{5}}$ Professor and Head, ${ }^{\mathbf{1}, \mathbf{2 , 4}, \mathbf{5}}$ Dept. of Neurology, ${ }^{3}$ Dept. of \\ Community Medicine, M.S. Ramaiah Medical College, Bengaluru, Karnataka, India
}

*Corresponding Author:

Email: mahendrajv@gmail.com

\begin{abstract}
Introduction: Seizures and antiepileptic drugs both can contribute to sexual dysfunction. Seizures can modify sexual behavior by altering the release of hypothalamic or pituitary hormones, by disrupting the function of limbic cortex. Antiepileptic drugs can alter hormonal release and may have direct inhibitory effects. Though Epilepsy is a common disease in neurological practice, there are very few studies available regarding sexual dysfunction in epilepsy.

Material and Methods: This cross sectional study was carried out on 100 patients of epilepsy with an age group between 25-50 years who presented as outpatient in the department of Neurology at M.S. Ramaiah Memorial Hospital, Bangalore, over two years. We also compared these cases with age matched normal people as a control. Pre-designed and pre-tested questionnaires like Arizona sexual experience scale, international index of erectile function questionnaire were used to collect data. Arizona sexual experience scale of $>15$ considered sexual dysfunction, $<15$ normal.

Results: Out of 100 cases with epilepsy, 43 patients were male (43\%), while 57 patients were female (57\%). Out of 100 normal cases, 61 were male (61\%), while 39 were female $(39 \%) .38 \%$ of epilepsy patient had sexual disturbance. Polytherapy was associated with sexual dysfunction (p-0.016).

Conclusion: Reduction of the frequency of epileptic seizures, and monotherapy is of great importance in improving the sexual health in epileptic patients.
\end{abstract}

Keywords: Seizures, Epilepsy, Sexual dysfunction, Anti epileptic drugs.

\section{Introduction}

Seizure is a clinical manifestation of abnormal hyper synchronous discharges of cortical neurons. Epilepsy is a minimum of two unprovoked seizures occurring more than 24 hours apart or one unprovoked seizure, and a probability of another seizure is similar to general recurrence risk after two unprovoked seizures over the next ten years or a diagnosis of an epilepsy syndrome. ${ }^{1}$ Sexual dysfunction is more prevalent (14$66 \%)$ in epilepsy; mainly with complex partial seizures. ${ }^{2}$ Seizures and antiepileptic drugs both can contribute to sexual dysfunction. Seizures can modify sexual behavior by altering the release of hypothalamic or pituitary hormones, by disrupting the function of limbic cortex. ${ }^{3}$ Antiepileptic drugs can alter hormonal release and may have direct inhibitory effects, mainly drugs like carbamazepine, phenytoin and sodium valproate. ${ }^{4}$ Though Epilepsy is a common disease in neurological practice, there are very few studies available regarding sexual dysfunction in epilepsy.

\section{Material and Methods}

This cross-sectional study was carried out on 100 patients with epilepsy with an age group between 25-50 years who presented as an outpatient in the department of Neurology at M.S. Ramaiah Memorial Hospital, Bangalore, over two years. We also compared these cases with age matched healthy people as a control. The institutional ethical committee approved the study.

Written informed consent obtained from all the participants of the study. Patients were eligible for selection if they were in age group between 20-50 years, if they were taking antiepileptic drugs for at least 1-year, and if they had regular sexual activity with a steady sexual partner for past1-year. Exclusion criteria were the history of psychiatric diseases, diabetes mellitus, hypertension, hypothyroidism, hyperthyroidism, evident urogenital diseases, other known neurological disorders and patients on antidepressants or drugs for erectile dysfunction.

A careful and detailed history was recorded and thorough clinical examination was conducted. Predesigned and pre-tested questionnaires like Arizona sexual experience scale, international index of erectile function questionnaire were used to collect data. Arizona sexual experience scale of $>15$ considered sexual dysfunction, $<15$ normal. $^{5}$ Statistical analysis data was analysed using SPSS Inc released 2009. PASW statistics for windows, version 18.0 Chicago. Chi square test was used to find the associated factors for sexual dysfunction in epilepsy. Logistic regression was applied to the factors which showed significant with $\mathrm{p}=0.10$. Value of $\mathrm{p}$ was considered statistically significant at $\mathrm{p}<0.05$

\section{Results}

Out of 100 cases with epilepsy, 43 patients were male $(43 \%)$, while 57 patients were female $(57 \%)$. Out of 100 healthy controls, 61 were male $(61 \%)$, while 39 were female $(39 \%)$. Male: Female ratio is $1: 1.32$ for epilepsy patients, whereas it is 1.56: 1 for normal subjects. 
The age group of the patients studied varied from $25-50$ years. Majority of the patients with epilepsy belonged to 25 - 30 years age group. Mean age of the patients with epilepsy was 33.5 years while that of normal subjects was 33.82 years.

Table 1: Percentage of patients according to seizure type

\begin{tabular}{|l|c|c|}
\hline \multicolumn{1}{|c|}{ Seizure type } & $\begin{array}{c}\text { No. of } \\
\text { Patients } \\
(\mathbf{n = 1 0 0 )}\end{array}$ & $\begin{array}{c}\text { Percentage of } \\
\text { Patients (\%) }\end{array}$ \\
\hline GTCS & 38 & 38 \\
\hline CPS & 37 & 37 \\
\hline $\begin{array}{l}\text { Simple partial } \\
\text { seizures }\end{array}$ & 18 & 18 \\
\hline $\begin{array}{l}\text { Juvenile Myoclonic } \\
\text { epilepsy (JME) }\end{array}$ & 7 & 7 \\
\hline
\end{tabular}

Out of 100 cases studied, majority of the patients with epilepsy had Generalised Tonic Clonic Seizures (GTCS). The next common presentation was complex partial seizures (CPS).
Table 2: Patients of epilepsy on number of Anti epileptic drugs (AED)

\begin{tabular}{|c|c|c|}
\hline No. of AED & $\begin{array}{c}\text { No. of Patients } \\
(\mathbf{n = 1 0 0})\end{array}$ & $\begin{array}{c}\text { Percentage of } \\
\text { Patients (\%) }\end{array}$ \\
\hline 1 & 29 & 29 \\
\hline 2 & 55 & 55 \\
\hline 3 & 14 & 14 \\
\hline 4 & 2 & 2 \\
\hline
\end{tabular}

Majority of the patients of epilepsy studied (55\%), were on 2 AED's. $29 \%$ of the patients were on monotherapy. We had $14 \%$ of the patients on 3 AED's. Only $2 \%$ of patients were on 4 AED's.

Table 3: Sexual Disturbance in epilepsy

\begin{tabular}{|l|c|c|}
\hline $\begin{array}{c}\text { Sexual } \\
\text { Disturbance }\end{array}$ & $\begin{array}{c}\text { No. of Patients } \\
(\mathbf{n = 1 0 0})\end{array}$ & $\begin{array}{c}\text { Percentage of } \\
\text { Patients (\%) }\end{array}$ \\
\hline Normal & 62 & 62 \\
\hline Abnormal & 38 & 38 \\
\hline
\end{tabular}

$38 \%$ of epilepsy patient had sexual disturbance

Table 4: Sexual Disturbance in normal subjects

\begin{tabular}{|l|c|c|}
\hline $\begin{array}{c}\text { Sexual } \\
\text { Disturbance }\end{array}$ & $\begin{array}{c}\text { No. of Patients } \\
(\mathbf{n = 1 0 0})\end{array}$ & $\begin{array}{c}\text { Percentage of } \\
\text { Patients (\%) }\end{array}$ \\
\hline Normal & 96 & 96 \\
\hline Abnormal & 4 & 4 \\
\hline
\end{tabular}

$4 \%$ of normal subjects had sexual disturbance

Table 5: Comparison of different parameters in epilepsy patients with and without sexual dysfunction

\begin{tabular}{|c|c|c|c|c|c|}
\hline \multirow{2}{*}{\multicolumn{2}{|c|}{ Characteristics }} & \multicolumn{2}{|c|}{ Sexual dysfunction } & \multirow{3}{*}{$\begin{array}{c}\text { Uni-Variate } \\
\text { P - value } \\
0.233\end{array}$} & \multirow{3}{*}{$\begin{array}{c}\begin{array}{c}\text { Multiple } \\
\text { Regression }\end{array} \\
\text { P - value } \\
\end{array}$} \\
\hline & & \multirow{2}{*}{$\begin{array}{c}\text { Yes } \\
12(28.6 \%) \\
25(45.5 \%) \\
1(33.3 \%) \\
\end{array}$} & \multirow{2}{*}{$\begin{array}{c}\text { No } \\
30(71.4 \%) \\
30(54.5 \%) \\
2(66.7 \%) \\
\end{array}$} & & \\
\hline $\begin{array}{c}\text { Age } \\
\text { (In years) }\end{array}$ & $\begin{array}{c}<30 \\
31-45 \\
>45\end{array}$ & & & & \\
\hline Sex & $\begin{array}{c}\text { Male } \\
\text { Female }\end{array}$ & $\begin{array}{l}19(31.7 \%) \\
19(47.5 \%)\end{array}$ & $\begin{array}{l}41(68.3 \%) \\
21(52.5 \%)\end{array}$ & 0.110 & - \\
\hline $\begin{array}{l}\text { Type of } \\
\text { Seizures }\end{array}$ & $\begin{array}{c}\text { JME } \\
\text { Focal } \\
\text { seizures } \\
\text { GTCS } \\
\text { CPS }\end{array}$ & $\begin{array}{c}3(42.9 \%) \\
7(38.9 \%) \\
13(34.2 \%) \\
15(40.5 \%)\end{array}$ & $\begin{array}{c}4(57.1 \%) \\
11(61.1 \%) \\
25(65.8 \%) \\
22(59.5 \%)\end{array}$ & 0.938 & - \\
\hline $\begin{array}{c}\text { Duration of } \\
\text { Seizures } \\
\text { (Years) }\end{array}$ & $\begin{array}{l}\leq 10 \\
>10\end{array}$ & $\begin{array}{l}27(32.9 \%) \\
11(61.1 \%)\end{array}$ & $\begin{array}{c}55(67.1 \%) \\
7(38.9 \%)\end{array}$ & 0.026 & 0.227 \\
\hline No. of AED & $\begin{array}{c}1 \\
2 \\
\geq 3\end{array}$ & $\begin{array}{c}4(13.8) \\
27(49.1) \\
7(43.8)\end{array}$ & $\begin{array}{c}25(86.2) \\
28(50.9) \\
9(56.3) \\
\end{array}$ & 0.006 & $0.016^{*}$ \\
\hline
\end{tabular}

Polytherapy is associated with sexual dysfunction, which is statistically significant.

\section{Discussion}

Our study showed $38 \%$ of patients with epilepsy, majority on polytherapy and $4 \%$ of normal age matched control had sexual dysfunction. This dysfunction was more in epilepsy patients in comparison to healthy controls. The prevalence of epilepsy with sexual dysfunction in literature ranges widely from $30-66 \%$ in men to $14-72 \%$ in women. ${ }^{6-8}$ Sexual dysfunction is 
mainly noted in drug resistant epilepsy, patients on polytherapy, and with comorbidities. ${ }^{9}$

Sexual dysfunction in males reported as lack of desire, lack of arousal and impotence, in females it is mainly arousal insufficiency and dyspareunia. These are common in patients with complex partial seizures, ${ }^{2}$ sexual disturbance scores were more in the right-sided temporal lobe epilepsy in comparison to left temporal onset. $^{12,13}$ Sexual dysfunction was more frequent in patients with seizures arising from hippocampus and amygdala. ${ }^{10,11}$ Our study showed sexual dysfunction in $40.54 \%$ of patients with complex partial seizures, other types of seizures had less sexual dysfunction

There are two schools of thought regarding the relationship of sexual dysfunction with antiepileptic drugs. Some studies show antiepileptic drugs as the cause of sexual dysfunction, and the others indicate that sexual dysfunction has no significant correlation with antiepileptic drugs and it arises with the onset of epilepsy even before the treatment is initiated. ${ }^{7,14}$ Some studies have even proved that sexual deficits improved when higher dose of antiepileptic are used to control seizures. ${ }^{10}$ Our study agrees with the previous studies, which have found significant correlation between polytherapy and sexual dysfunction. Study by Oliver J Henning in Norway described higher prevalence of sexual problems in patients with epilepsy (women: $75.3 \%$ vs $12 \%$; men: $63.3 \%$ vs $9.6 \%)^{15}$ our patients on polytherapy had refractory seizures, uncontrolled seizures might have also contributed to sexual dysfunction.

Antiepileptic drugs reduce the bioavailability of testosterone and estrogen.

Epileptic Women or men with low testosterone have higher chances of sexual dysfunction, in the form of decreased arousal. Low estrogen levels also causes sexual dysfunction due to lack of lubrication leading to dyspareunia and vaginismus. ${ }^{7,14}$ Studies have shown that carbamazepine or phenytoin causes lower bioavailability of testosterone and estrogen than lamotrigine leading to reduced sexual function. ${ }^{7}$

The limitation in our study was we did not do hormonal assays, and diversity of anti epileptic drug treatment did not allow us to compare individual AED in our patient.

\section{Conclusion}

Our study indicates that sexual dysfunction is seen more frequently in patients with epilepsy. Monotherapy significantly reduces sexual dysfunction as compared to polytherapy in the treatment of epilepsy.

\section{References}

1. Fisher RS, Acevedo C, Arzimanoglou A, et al. ILAE official report: a practical clinical definition of epilepsy. Epilepsia 2014;55(4):475-82. doi:10.1111/epi.12550.

2. Morrell MJ. Sexual Dysfunction in Epilepsy. Epilepsia 1991;32(s6):S38-S45. doi:10.1111/j.152857.1991.tb05891.x.

3. Franceschi M, Perego L, Cavagnini F, et al. Effects of Long-Term Antiepileptic Therapy on the HypothalamicPituitary Axis in Man. Epilepsia 1984;25(1):46-52. doi:10.1111/j.1528-1157.1984.tb04154.x.

4. Lambert MV. Seizures, hormones and sexuality. Seizure 2001;10(5):319-340. doi:10.1053/seiz.2000.0512.

5. McGahuey CA, Gelenberg AJ, Laukes CA, et al. The Arizona Sexual Experience Scale (ASEX): Reliability and Validity. J Sex Marital Therapy. 2011;26(1):25-40. doi:10.1080/009262300278623.

6. Demerdash A, Shaalan M, Midani A, Kamel F, Bahri M. Sexual Behavior of a Sample of Females with Epilepsy. Epilepsia 1991;32(1):82-5. doi:10.1111/j.15281157.1991.tb05616.x.

7. Herzog AG, Drislane FW, Schomer DL, et al. Differential effects of antiepileptic drugs on sexual function and hormones in men with epilepsy. Neurol 2005;65(7):101620. doi:10.1212/01.wnl.0000178988.78039.40.

8. Sathyanarayana Rao TS, Karan V, Harsha S, Keshava BS, Pradeep R, Andrade C. Sexual dysfunction in women with epilepsy. Ind J Psychiatry 2015;57(3):301. doi:10.4103/0019-5545.166616.

9. Zelená V, Kuba R. 122. Sexual dysfunction in women with epilepsy. Epilepsy Behav 2010;17(4):615. doi:10.1016/j.yebeh.2010.01.147.

10. BLUMER D, WALKER AE. Sexual Behavior in Temporal Lobe Epilepsy: A Study of the Effects of Temporal Lobectomy on Sexual Behavior. Arch Neurol 1967;16(1):37-43. doi:10.1001/archneur.1967.00470190041005.

11. Daniele A, Azzoni A, Bizzi A, Rossi A, Gainotti G, Mazza S. Sexual behavior and hemispheric laterality of the focus in patients with temporal lobe epilepsy. Biological Psychiatry 1997;42(7):617-24. doi:10.1016/S0006-3223(96)00411-8.

12. Herzog AG, Coleman AE, Jacobs AR, et al. Relationship of sexual dysfunction to epilepsy laterality and reproductive hormone levels in women. Epilepsy Behav 2003;4(4):407-13. doi:10.1016/S1525-5050(03)00121-5.

13. Hierons R, Saunders M. IMPOTENCE IN PATIENTS WITH TEMPORAL-LOBE LESIONS. The Lancet 1966;288(7467):761-64. doi:10.1016/S01406736(66)90361-8.

14. Morrell MJ, Flynn KL, Doñe S, Flaster E, Kalayjian L, Pack AM. Sexual dysfunction, sex steroid hormone abnormalities, and depression in women with epilepsy treated with antiepileptic drugs. Epilepsy Behav 2005;6(3):360-65. doi:10.1016/j.yebeh.2005.01.004.

15. Oliver J Henning, Karl O. Nakken, Bente Traeen et. al. Sexual problems in people with refractory epilepsy. Epliepsy Behav 2016;61:174-179 